\title{
Proximate and sensory analysis of wheat bread supplemented with Nigella sativa oil and Nigella sativa extract
}

Palwasha Khali1 ${ }^{1}$, Sara Masood ${ }^{1 *}$, Attiq ur Rehman ${ }^{2,3}$, Ayesha Zafar Iqbal $^{4}$, Zeenat Islam ${ }^{1}$, Nida Javaid ${ }^{1}$, Amina Ilyas ${ }^{5}$, Shanzay Qamar ${ }^{6}$ and Aurang Zeb ${ }^{1}$

1. University Institute of Diet and Nutritional Sciences (UIDNS), Faculty of Allied Health Sciences, University of Lahore, Lahore-Pakistan

2. Natural Resources Institute (Luke), Horticulture Technologies, Production Systems Unit, Toivonlinnantie 518, FI-

21500 Piikkiö-Finland

3. Department of Agricultural Sciences, The University of Helsinki, FI- 00790 Helsinki-Finland

4. Allied Health Sciences, Akhtar Saeed Medical and Dental College, Lahore-Pakistan

5. Department of Botany, Government College University, Lahore-Pakistan

6. Department of Bioinformatics \& Biotechnology, Government College University Faisalabad-Pakistan

*Corresponding author's email: sarah.13494@gmail.com

\section{Citation}

Palwasha Khalil, Sara Masood, Attiq ur Rehman, Ayesha Zafar Iqbal, Zeenat Islam, Nida Javaid, Amina Ilyas, Shanzay Qamar and Aurang Zeb. Proximate and sensory analysis of wheat bread supplemented with Nigella sativa oil and Nigella sativa extract. Pure and Applied Biology. Vol. 10, Issue 4, pp1158-1165.

http://dx.doi.org/10.19045/bspab.2021.100122

\begin{tabular}{llll}
\hline \hline Received: 04/11/2020 & Revised: 22/01/2021 & Accepted: 28/01/2021 & Online First: 02/02/2021 \\
\hline \hline
\end{tabular}

\section{Abstract}

Wheat is one of the important food crops worldwide while wheat bread is the most commonly consumed form of it in different populations. As Nigella sativa is rich in several phytochemicals that possess disease preventive properties hence, the proximate and sensory analysis of the breads supplemented with Nigella sativa extract and oil have been discussed in this study. Nigella sativa is one of the famous medicinal plants that has been used for treatment of various illnesses in different parts of the world. Compositional analysis revealed that Nigella sativa extract supplemented bread contains $14.75 \%$ moisture content, $10.32 \%$ crude fat content, $4.40 \%$ ash and $3.55 \%$ crude fiber, $11.89 \%$ crude protein and 55.09\% Nitrogen Free Extract (NFE). In comparison, analysis of Nigella sativa oil supplemented revealed that it contains $14.23 \%$, moisture content, $10.53 \%$ crude fat content, $4.10 \%$ ash and $3.20 \%$ crude fiber, $11.79 \%$ crude protein and $56.15 \%$ NFE. Sensory evaluation was evaluated using 9 points-hedonic scale. Maximum score for overall acceptability was recorded for Nigella sativa extract fortified bread. In the meantime, the requests for wheat-based items with value addition are developing quickly in the previous couple of decades, as customers understood that eating foods with medical advantages is superior to taking medicine. The breads fortified with Nigella sativa will not only meet the consumer demands in terms of sensory attributes but might also aid in improving their health.

Keywords: Bread; Food fortification; Nigella sativa; Proximate composition; Sensory attributes Introduction

The problem of nutritional insufficiency in most of the developed countries is 
deteriorating with every passing day. It intensifies the need to consider strategic use of food sources that are nutritious and cheap to manage in order to control and prevent health problems. Fortifying nutritionally inadequate food items can improve their dietary properties [1]. Wheat being the most important crop of the world [2] has a special position among the bakery goods and is considered the most common and staple cereal-based food [3]. Due to its nutritional quality and sensory properties, it is consumed as the basic part of human diet from centuries. Bread is made of wheat flour [4] and can be fortified with other cereals-based flour such as sorghum, rice, maize, and barley etc. to increase its nutritional quality [5]. In countries where bread wheat is not the main domestic crop, efforts can be made to replace wheat flour with other types of available flours to overcome nutritional deficiencies [6]. Bread is a fermented food product made from wheat flour, yeast, water and salt by various methods such as mixing, kneading, shaping, fermenting, baking and finally cutting. Examination of characteristics of a loaf is crucial in order to evaluate the quality of a bread. Since formulation and production of fortified cereal-based items is increasing constantly; it is very essential to identify and explore sensory and quality characteristics of such foods.

Cereals, can prevent malnutrition and related health risk by providing essential nutrients; in fact, such plants have been used for traditional remedies since long in the history of mankind as well as in modern medicines [7]. As stated by World Health Organization (WHO), around three fourth of the population in underdeveloped nations rely on therapeutic plants to provide crucial care due to the fact that more than $60 \%$ of them either don't have access or can't afford allopathic medicines [5]. At present, there in renewed interest in the use of plants as a food source and medicine has occurred [8]. Biofortification has also been suggested to improve nutritional status of marginalized societies by agronomic, breeding and transgenic modification of plants [9]. Whereas, the use of phytomedicines for the treatment of various illnesses has been elevated dramatically due to their ease of accessibility, low cost and the certainty that the natural therapies have scarcer side effects than artificially produced remedies [10]. Formulation and development of novel food products by using naturally occurring food sources is also supported and encouraged due to the fact that there exist about 300,000 species of herbs globally among which only 15 percent have been tested for their pharmacological potential [11].

Nigella sativa L. (Ranunculaceae) is historically believed to be one of the strongest and highly valuable herbs globally. Such a rich dietary value of black seeds can be associated with the presences of significant quantity of protein, fiber, minerals \& vitamins [12, 13]. Different sources have revealed the nutritional composition of black cumin seeds as $20-85 \%$ protein, $38.20 \%$ fat, 7- $94 \%$ fiber and $31.94 \%$ total carbohydrate. Including various other identified amino acids such as glutamate, arginine, and aspartate in major while cysteine and methionine in minor quantities. The seeds of this herb constitute remarkable levels of minerals such as iron, copper, zinc, phosphorus, calcium, thiamine, niacin, pyridoxine, and folic acid as well [14]. Moreover, hundreds of phyto components have been displayed upon phytochemical analysis of Nigella sativa that mainly include alkaloids, saponins, sterols and essential oils $(0.4 \%-2.5 \%)$ [15]. It also contains $26-34 \%$ fixed oil of which the key fatty acids are linoleic acid (64.6\%) and palmitic acid $(20.4 \%)$. Including various active constituents reported so far, thymoquinone is believed to be a major biologically active 
component exhibiting a long list of therapeutic benefits [16, 17]. Therefore, present study was planned to formulate breads containing different percentages of Nigella sativa oil or Nigella sativa extract and to examine them for their sensory attributes.

\section{Materials and Methods}

This research study was conducted at the University Institute of Diet and Nutritional Sciences (UIDNS), Faculty of Allied Health Sciences, University of Lahore, Lahore, Pakistan.

\section{Preparation of Nigella sativa Powder}

Nigella sativa seeds were bought from a local herb store in Lahore, Pakistan. The seeds were dried at room temperature and grounded to a fine powder using electrical grinder and stored until further use.

\section{Nigella sativa oil}

Fine quality Nigella sativa seed oil was purchased from a local store in Lahore, Pakistan.

\section{Preparation of Nigella sativa extract}

Black seeds were extracted with $60 \%$ ethanol, maintained to $\mathrm{pH} 5.5$ at $50^{\circ} \mathrm{C}$ for a period of 3 hours. The extract was then kept in an airtight test tube and stored in refrigerator until further use.

\section{Bread making}

Three types of breads were made; a control bread (Bread A), one with Nigella sativa extract (Bread B), and one with Nigella sativa oil (Bread C). Refined wheat flour (900gm) was used for all types of bread formulations while breads supplemented with Nigella sativa oil or Nigella sativa extract were prepared by replacing corresponding amount of wheat flour in the formulation $(0.3 \%$ of flour for black seed powder extract enriched bread) and $0.875 \%$ of flour for black seed oil enriched bread). To each bread formulation water, salt and yeast were added to make respective dough(s). The dough was mixed using a spiral mixture for 7 minutes and stored for fermentation. Small batches of dough $(300 \mathrm{gm})$ were baked in preheated oven at $180{ }^{\circ} \mathrm{C}$ for 35 minutes and then cool down for 24 hours at room temperature.

\section{Screening of participants}

Participants were screened using a questionnaire along and practical test in asking participants to identify the five basic tastes. An inclusion criterion was given as:

- Probability of the nature of product

- The participant are the ones who consume the product regularly

- The participant could distinguish between five basic tastes; sweet, bitter, sour, salty, umami and could detect a neutral sample

Finally, 7 participants were included in the sensory evaluation panel.

\section{Training of Panel}

The participants were invited to the test about a week before the session. The invitations contained instructions that needed to be followed before the test i.e.

- Try not to smoke, consume coffee, tea or spicy food close to the test session.

- Try not to wear strong scented perfumes or hairsprays.

- Try not to be too full or too hungry during the test session.

- Before and after testing each sample, rinse mouth with water

\section{Proximate analysis}

The analysis of crude protein, crude fiber, crude fat and moisture content of three types of bread formulations was carried out by following appropriate various methods. Three repetitions were performed for each type of test in this study.

\section{Moisture content}

The moisture content of the breads sample was carried out as given by the Association of Official Analytical Chemists [18].Weighed $5 \mathrm{~g}$ of the bread formulations was kept in an air-oven at $100^{\circ} \mathrm{C}$ overnight for drying to carry out the procedure for determining the moisture content. 


\section{Fat content}

Weighed $10 \mathrm{~g}$ of bread samples were dried overnight in the oven first to remove the moisture. After the removal of moisture, the oil was extracted in a Soxhlet apparatus for about 5 to 6 hours using n-hexane as solvent [18].

\section{Protein content}

For the estimation of protein content in the breads $5 \mathrm{~g}$ of the sample was treated by the Kjeldahl method. In the end of the procedure the protein was calculated with the help of a nitrogen factor i.e. 6.25 which was given by [18].

\section{Ash content}

Weighed $10 \mathrm{~g}$ sample of each of the respective bread was oven dried overnight to remove moisture. Then the sample was ignited in order to remove carbon and placed in a muffle furnace at $550 \mathrm{oC}$ for about $4-5$ hours [18]. The result was presented as percentage of dry matter.

\section{Nitrogen free extract (NFE)}

The nitrogen free extract of the bread samples was obtained by subtracting the sum of total moisture, fat, ash, protein and fiber from 100.

\section{Fiber content}

Weighed $5 \mathrm{~g}$ of various bread samples was evaluated by the help of the standard method of [18] which included calculating the weight loss residue obtained after the digestion of the defatted sample with first 1.25 M H2SO4 and then with $1.25 \mathrm{M}$ of $\mathrm{NaOH}$ under specific conditions.

\section{Statistical analysis}

Mean and standard deviation values were calculated from all the scores for each attribute of panelist evaluation for all three bread formulations. All data were subjected to Analysis of Variance (ANOVA). The mean values were compared with Tukey HSD test and the statistical significance was defined as $\mathrm{P} \leq 0.05$ [19]. Statistical analysis was done by using SPSS Version 25.0 [20].

\section{Results and Discussion \\ Sensory analysis of breads}

Sensory scores were noted for five different bread attributes from the trained panel. The (Table 1) shows the result of sensory evaluation with mean and standard deviation differences of three breads made with plain flour, Nigella sativa extract and Nigella sativa oil. The differences in the composition of Nigella sativa extract and Nigella sativa oil made breads different in taste, texture, appearance, odour as well as overall acceptability. A clustered bar chart is also presented in (Fig. 1) showing the overall distribution of means on the basis of all the attributes of evaluation by the panellist for three types of bread formulations. Sensory assessment uncovered that the breads enhanced with Nigella sativa extract demonstrated most noteworthy scores for general acceptability $(8.43 \pm 0.53)$ whereas the plain bread has shown the lowest mean value $(6.57 \pm 0.53)$ in terms of overall acceptability. On the other hand, Nigella sativa oil supplemented bread have shown an intermediate mean score $(7.00 \pm 0.82)$ for overall acceptability by the panel, In the current study bread B $(8.14 \pm 0.90)$ showed the best in taste followed by bread C $(6.86 \pm 0.90)$ and the lowest taste values was found in the control bread group (5.71 \pm 0.76$)$.Textures determine the quality of the product. The results indicated that bread $\mathrm{B}(8 \pm 0.63)$ is ranked as the best in comparison with other samples bread $\mathrm{C}(6.67 \pm 0.52)$ and bread A $(5.67 \pm 0.82)$ in terms of texture by the panelists. Appearance is the most important parameter as it is the first thing human eye attracts the most. In present study the appearance scores for bread B $(8.29 \pm 0.76)$ was much good followed by bread C (7.00 \pm 0.82$)$. The lowest values for appearance was shown in bread A (5.71 \pm 0.95$)$. The odour of bread was affected with increase in flour amount used to make bread. The bread B $(8.29 \pm 0.76)$ shows the highest score for the 
aroma followed by bread C $(6.57 \pm 0.53)$ and the lowest value of odor was shown in bread A (5.57 \pm 0.53$)$. The bread supplemented of with Nigella sativa oil or Nigella sativa concentrate improves its nutritional properties when compared with the control bread. Another similar study was conducted on the sensory evaluation of Nigella sativa supplemented breads and found that substitution of $5 \%$ of flour in bread with Nigella sativa depicted satisfactory consumer acceptability in terms of flavor, texture, aroma and overall acceptability [21]. Ligarnasari et al. (2018) reported that addition of Nigella sativa oil in brownies improved their sensory attributes [22]. Melapa (2015) have reported that soft texture of the product is influenced by its water content, fat as well as protein content and the use of baking ingredient [23]. Black seed oil has been reported to contain oleic acid, lauric acid, limonene $(2.57 \%)$, linoleic acid $(57.24 \%)$, jupine $(0.83 \%)$, palmitic acid $(3.11 \%)$, and thymoquinone $(13.80 \%)$ and these constituents have potential to improve texture of the food product [24]. The substitution of extract and oil didn't reduce the moisture content of the bread and hence fortified breads maintained the softness that was comparable with the plain bread. According to Cauvain et al. (2006) the water content of a product can improve its softness [25] as the high moisture content in the material will cause the texture of the product to become softer.

Table 1. Mean and standard deviation values of four parameters and overall acceptability of three types of bread formulations when subjected to the panel for evaluation on a hedonic scale (0-9)

\begin{tabular}{|c|c|c|c|c|c|}
\hline $\begin{array}{c}\text { Formulation of } \\
\text { bread(s) }\end{array}$ & Appearance & Taste & Texture & Odour & $\begin{array}{c}\text { Overall } \\
\text { acceptability }\end{array}$ \\
\hline A & $5.71 \pm 0.95$ & $5.71 \pm 0.76$ & $5.67 \pm 0.82$ & $5.57 \pm 0.53$ & $5.67 \pm 0.82$ \\
\hline B & $8.29 \pm 0.76^{*}$ & $8.14 \pm 0.90^{*}$ & $8.00 \pm 0.63^{*}$ & $8.29 \pm 0.76^{*}$ & $8.17 \pm 0.75^{*}$ \\
\hline C & $7.00 \pm 0.82$ & $6.86 \pm 0.90$ & $6.67 \pm 0.52$ & $6.57 \pm 0.53$ & $6.83 \pm 0.75$ \\
\hline
\end{tabular}

Where A refers to control bread. B refers to bread supplemented with Nigella sativa extract, and C refers to bread supplemented with Nigella sativa oil. * shows significant difference at $\mathrm{P}<0.05$ by using Tukey HSD

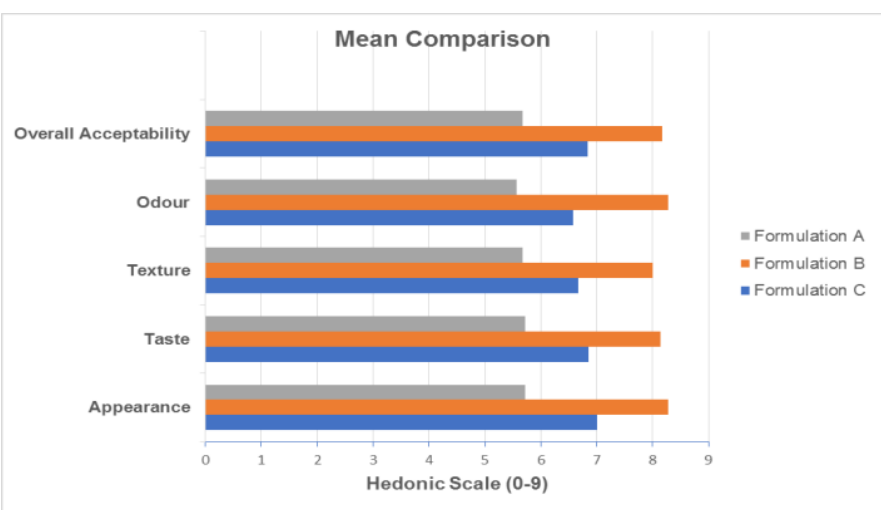

Figure 1. Mean values of different attributes of the various studied bread formulations, scored by trained panel on a hedonic (0-9) scale. A refers to control bread, B refers to bread supplemented with Nigella sativa extract, and $C$ refers to bread supplemented with Nigella sativa oil 


\section{Proximate analysis of breads}

Nigella sativa supplemented breads nutritional composition has been mentioned below in (Table 2). The detected mean value result of proximate composition of Nigella sativa extract bread shows that it contain $14.75 \%$ moisture content, $10.32 \%$ crude fat content, $4.40 \%$ ash and $3.55 \%$ crude fiber, $11.89 \%$ crude protein and $55.09 \%$ NFE, while for Nigella sativa oil supplemented bread the content of moisture, ash, crude fat, crude protein, crude fiber and NFE was $14.23 \%, 4.10 \%, 10.53 \%, 11.79 \%, 3.20 \%$ and $56.15 \%$ respectively. The results showed that substitution of wheat flour with Nigella sativa extract and Nigella sativa oil has no major impact on the overall proximate composition of bread. However, replacing wheat flour with Nigella sativa extract led to slight escalation in the fiber and ash content of the bread enriched with Nigella sativa extract. The comparatively increased content of ash and fiber in Nigella sativa extract supplemented bread might be due to the presence of various minerals in Nigella sativa. The proximate composition of sample breads can also be contrasted with those described by [26] which reported that plain wheat bread has moisture $27.4 \%$ protein 5.96 $\%$ fat $7.19 \%$, crude fiber $0.49 \%$ ash $2.22 \%$ and carbohydrate $57.17 \%$. It could be seen in (Table 2) that moisture content of all types of bread was more or less similar. The NFE content of control bread sample was reported to be highest while it was lowest for Nigella sativa extract supplemented bread. In terms of moisture and carbohydrate content similar findings were reported by Pawase et al. (2020), who evaluated the effect of Nigella sativa fortification in cookies [27].

Table 2. Proximate composition of breads used in study

\begin{tabular}{|c|c|c|c|}
\hline Proximate Composition & Plain bread & $\begin{array}{c}\text { Nigella sativa extract } \\
\text { bread }\end{array}$ & $\begin{array}{c}\text { Nigella sativa oil } \\
\text { bread }\end{array}$ \\
\hline Moisture (\%) & $14.38 \pm 0.14$ & $14.71 \pm 0.08$ & $14.20 \pm 0.07$ \\
\hline Ash (\%) & $3.64 \pm 0.03$ & $4.37 \pm 0.11$ & $4.25 \pm 0.21$ \\
\hline Crude fat (\%) & $10.18 \pm 0.07$ & $10.30 \pm 0.09$ & $10.51 \pm 0.11$ \\
\hline Crude fiber (\%) & $3.06 \pm 0.14$ & $3.54 \pm 0.12$ & $3.19 \pm 0.04$ \\
\hline Crude Protein (\%) & $11.50 \pm 0.05$ & $11.85 \pm 0.16$ & $11.77 \pm 0.07$ \\
\hline Nitrogen free extract (\%) & $57.21 \pm 0.11$ & $55.21 \pm 0.10$ & $56.05 \pm 0.12$ \\
\hline
\end{tabular}

\section{Conclusion}

Explicit logical techniques have been created to precisely, reproducibly, and impartially measure or gauge human reactions to stimuli. Like and abhorrence are by all account not the only questions that are answered by tactile investigation. Buyer discernment and enthusiastic reactions can likewise be addressed, the effect of storage, fixing substitution, and bundle and procedure inconstancy can be resolved, and connections can be set up between instrumental tests and tactile observation. The sensory analysis showed significant differences between control bread and supplemented breads in all the determined sensory attributes. Present study concludes that sensorial properties of supplemented bread sample i.e. bread sample prepared from the substitution of whole wheat flour with Nigella sativa extract perceived better score for all attributes in comparison to control bread and Nigella sativa oil supplemented bread. The nutrient components found in Nigella sativa are essentials for the human body as they provide the required amount of nutrients such as 
carbohydrates, protein and fats. Therefore, it can be a great strategy to add it as a functional supplement in bread.

\section{Authors' contributions}

Conceived and designed the experiments: $\mathrm{P}$ Khalil, S Masood, A Zeb \& AU Rehman, Performed the experiments: $P$ Kahlil, $S$ Masood, AZ Iqbal, Z Islam \& S Qamar, Analyzed the data: AU Rehman, S Qamar \& A Ilyas, Contributed materials/ analysis/ tools: A Zeb, Wrote the paper: P Khalil, S Masood, A Ilyas \& AU Rehman.

\section{References}

1. Hajbaghery MA \& Rafiee S (2018). Medicinal plants use by elderly people in Kashan, Iran. Vol 7. Nurs Midwifery Stud 2: 67-73.

2. Rehman AU, Khalil IH \& Ali I (2020). Genetic diversity and traits association in tetraploid and hexaploid wheat genotypes in in Khyber Pakhtunkhwa Province of Pakistan. Sarhad J of Agr 36(4): 1112-1118.

3. Haseena S, Aithal M, Das KK \& Saheb SH (2015). Phytochemical analysis of Nigella sativa and its effect on reproductive system. J Phar Sci Res 8: 514-517.

4. Taylor JRN (2004). Grain production and consumption: Africa. In: Encyclopedia of Grain Science (edited by $\mathrm{CC}$ Wrigley, $\mathrm{HH}$ Corke \& $\mathrm{CE}$ Walker). London: Elsevier pp. 70-78.

5. Mohamed AA, Xu J \& Singh (2010). M Yeast leavened banana-bread: formulation, processing, color and texture analysis. Food Chem 118: 620626.

6. Ahmed MS, Hussein M, Kamil M, Nefisa A, Hegaz SAH \& Abo El-Nor (2013). Effect of Wheat Flour Supplemented with Barely and/or Corn Flour on Balady Bread Quality. Pol J food Nutr Sci 63: 121-157.

7. Farooq AGM, Hussain MA, Zengin G, Alkharfy KM, Ashraf M \& Gilani AH
(2016). Capparis spinosa L.: a plant with high potential for development of functional foods and nutraceuticals/pharmaceuticals. Int $J$ Pharmacol 12: 201-19.

8. Hadi MY, Mohammed GJ \& Hameed IH (2016). Analysis of bioactive chemical compounds of Nigella sativa using gas chromatography-mass spectrometry. $J$ of Pharmacog and Phytother 8(2): 8-24.

9. Rehman, AU, Masood S, Khan NU, Abbasi ME, Hussain Z \& Ali I (2020). Molecular basis of Iron Biofortification in crop plants; A step towards sustainability. Plant Breeding pp. 1-11.

10. Hajbaghery MA and Rafiee S (2018). Medicinal plants use by elderly people in Kashan, Iran. Nurs Midwifery Stud 7(2): 67-73.

11. Mohamed AA, Xu J \& Singh (2010). M. Yeast leavened banana bread: formulation, processing, color and texture analysis. Food Chem 118: 620626.

12. Sarac G, Kapicioglu Y, Sener S, Mantar I, Yologlu S, Dundar C, Turkoglu M \& Pekmezci E (2019). Effectiveness of topical Nigella sativa for vitiligo treatment. Dermatol Ther 25: 12949.

13. Khalil P, Masood S, Rehman AU, Khalil F \& Nawaf J (2020). Preventive Role of Thymoquinone against Certain Chronic Health Issues: A Review. Int J Nutr Sci 5(4): 155-162

14. Hadi MY, Mohammed GJ \& Hameed IH (2016). Analysis of bioactive chemical compounds of Nigella sativa using gas chromatography-mass spectrometry. $J$ of Pharmacog and Phytother 8(2): 8-24.

15. Farooqui Z, Ahmed F, Rizwan S, Shahid F, Khan AA \& Khan F (2017). Protective effect of Nigella sativa oil on cisplatin induced nephrotoxicity and oxidative damage in rat kidney. Biomed Pharmacother 1(85): 7-15. 
16. Mamun MA \& Absar N (2018). Major nutritional compositions of black cumin seeds cultivated in Bangladesh and the physicochemical characteristics of its oil. Int Food Res J 25(6): 2634-2639.

17. Haseena S, Aithal M, Das KK \& Saheb SH (2015). Phytochemical analysis of Nigella sativa and its effect on reproductive system. J Phar Sci Res 8: 514-517.

18. AOAC (2006). Official Methods of Analysis, 18th ed. Association of Official Analytical Chemists, Arlington, VA, USA.

19. Masood S, Rehman AU, Bashir S, Imran M, Khalil P, Khursheed T, Iftikhar F, Hafiza M, Farooq S, Rizwan B \& Javaid $N$ (2020). Proximate and Sensory Analysis of Wheat Bread Supplemented with Onion Powder and Onion Peel Extract. Biosci Res 17(4): 4071-4078.

20. Armonk NY (2017). Version 25.O. SPSS. IBM Corp.

21. Osman MA, Alamri MS, Mohamed AA, Hussain S, Gassem MA \& Rahman IA (2014). Black cumin-fortified flat bread: formulation, processing, and quality. Qual Assur Saf Crops Foods 7(2): 2338.

22. Ligarnasari IP, Anam C \& Sanjaya AP (2018). Physical, chemical and sensory properties of brownies substituted with sweet potato flour (Ipomoea batatas L.) With addition of black cumin oil (Nigella sativa L.). InIOP Conference Series: Earth and Environm Sci, IOP Publ 102(1): 012084.

23. Melapa A, Djarkasi KJ \& Ludong $\mathrm{M}$ (2015). Acceptance of Panellists Against Brownies Roasted Raw of Daluga Bulbs Flour (Cyrtospermamerkussi Hassk) (Schott) Food Sci and Techn Stud P. pp. 13-16

24. Cedola A, Cardinali A, Del NMA \& Conte A (2019). Enrichment of bread with olive oil industrial by-product. $J$ Agric Sci Technol 9: 119-27.

25. Cauvain SP \& Young LS (2006) Baked Products: Science, Technology and Practice., Blackwell Publishing., United Kingdoms

26. Adubofuor J, Amoah I, Batsa V, Agyekum PB \& Buah JA (2016). Nutrient Composition and Sensory Evaluation of Ripe Banana Slices and Bread Prepared from Ripe Banana and Wheat Composite Flours. AM J Food Nutr 4(4): 103-111.

27. Pawase PA \& Veer SJ (2020) Utilization of Black cumin seed (Nigella sativa L.) fractions on quality characteristics of cookies. Int. J Pharm. Life Sci 1(1): 1622. 